Int. J. Electrochem. Sci., 12 (2017) $4428-4443$

\title{
Spontaneous Growth of Prussian Blue Nanoparticles on Three Dimensional Porous PEDOT for Enhanced Catalytic Reduction and Sensitive Detection of Hydrogen Peroxide
}

\author{
Min Yang ${ }^{1}$, Ying Liu ${ }^{1}$, Yonggui Song ${ }^{2}$, Guochun Zhao ${ }^{1}$, Haiyan Tan ${ }^{1}$, Qiuping Zhang ${ }^{1}$ \\ and Fugang $X u^{1, *}$ \\ ${ }^{1}$ Key Laboratory of Functional Small Organic Molecule, Ministry of Education, College of Chemistry \\ and Chemical Engineering, Jiangxi Normal University, 99 Ziyang Road, Nanchang 330022, China \\ ${ }^{2}$ Jiangxi University of Chinese Traditional Medicine, 56 Yangming Road, Nanchang 330006, China \\ *E-mail: fgxu@jxnu.edu.cn
}

doi: $10.20964 / 2017.05 .57$

Received: 28 November 2016 / Accepted: 5 February 2017 / Published: 12 April 2017

In this study, a new approach was developed to prepare a novel three dimensional macroporous poly(3,4-ethylene-dioxythiophene)-Prussian blue hybrid 3D-PEDOT-PB for sensitive $\mathrm{H}_{2} \mathrm{O}_{2}$ detection. 3D-PEDOT prepared by electrodeposition not only as a conductive matrix, but also as a reductant to initiate the spontaneously "electroless" deposition of PB and as scaffold with large surface area for firmly anchoring more PB NPs. The 3D macroporous structure of the hybrid also facilitates the electron transfer and mass transport. Due to the synergistic interaction between the 3D-PEDOT and the PB NPs, the hybrid shows remarkably enhanced activity for $\mathrm{H}_{2} \mathrm{O}_{2}$ reduction. A non-enzymatic $\mathrm{H}_{2} \mathrm{O}_{2}$ sensor with a high sensitivity $\left(981 \mu \mathrm{A} \cdot \mathrm{mM}^{-1} \cdot \mathrm{cm}^{-2}\right)$, a wide linear range $(0.17 \mu \mathrm{M}$ to $0.257 \mathrm{mM})$ and a low detection limit $(80 \mathrm{nM})$ was fabricated based on the 3D-PEDOT-PB hybrid. Furthermore, the prepared sensor displays a rapid, stable response and good selectivity. The simple preparation and advanced properties of the novel 3D-PEDOT-PB hybrid may have promising applications in electrochemical sensor, electrochromic device and so on.

Keywords: Prussian blue; hydrogen peroxide; PEDOT; electrochemical sensor; conducting polymer

\section{$\underline{\text { FULL TEXT }}$}

(C) 2017 The Authors. Published by ESG (www.electrochemsci.org). This article is an open access article distributed under the terms and conditions of the Creative Commons Attribution license (http://creativecommons.org/licenses/by/4.0/). 